MedieKultur | Journal of media and communication research | ISSN 1901-9726

Article - Theme section

\title{
Everyday elites, citizens, or extremists? Assessing the use and users of non-election political hashtags
}

\section{Anders Olof Larsson}

MedieKultur 2014, 56, 61-78

Published by SMID | Society of Media researchers In Denmark | www.smid.dk The online version of this text can be found open access at www.mediekultur.dk

As research has indicated, what are sometimes described as traditional forms of political-parliamentary participation are dwindling in most Western democracies, and the Internet has often been pointed to as harboring the means to hinder these developments. While empirical studies on these matters have at best provided mixed results, social media services, like Twitter, have yet again fanned the flames of the most enthusiastic debaters. This paper moves beyond the often-studied context of parliamentary elections and instead offers a structural study of everyday political discussions on Twitter. Specifically, tweets from political contexts in Sweden and Norway are collected and analyzed with a specific focus on the top users and their activities. Results indicate that while thematic Twitter discussions can indeed serve as a potential channel for citizens, the influence of established as well as political extremist actors is also clearly discerned.

\section{Introduction}

While it is problematic to provide precise temporal delimitations, the last few decades have seen declining trends regarding what is sometimes referred to as "electoral and conventional" participation (Anduiza, Cantijoch, \& Gallego, 2009, p. 863), practices that can be further understood as parliamentary-political engagement. Such "widespread disillusionment with democratic processes" (Giddens, 2002, pp. 71-72) can be traced across geographical borders 
among most industrialized countries, and it is often defined in terms of voter alienation, declining political party membership, and a supposed lack of participation in civil society (e.g., Calenda \& Meijer, 2009; Gil de Zúñiga, 2012; Kalnes, 2009; Putnam, 2000) - perhaps at least in part due to citizen cynicism towards politics as a repercussion of the sleek stylings of professionalized politics (e.g., Larsson, 2013a; Lilleker \& Koc-Michalska, 2012; Zittel, 2009).

These trends of citizen disenchantment have largely spread in parallel to the development and increased use of the Internet. As often in previous times of purported systemic crises, such technological advances are suggested as fixes, quick or not, for the societal maladies described above (e.g., Castells, 2004; Chadwick, 2006; Dahlberg, 2011; Himelboim, McCreery, \& Smith, 2013; Norris, 2002). As with television before (e.g., Polat, 2005; Tichenor, Donohue, \& Olien, 1970), early inquiry into the political uses of the Internet in the hands of citizens often conceptualized these appropriations as a means to "mobilize previously passive segments", helping them "bloom into both active and capable citizens" (H. S. Christensen \& Bengtsson, 2011, p. 2). Later, more empirically-focused research presented conflicting results regarding these issues (e.g., Bimber \& Copeland, 2013; Hindman, 2009; Skoric, Ying, \& Ng, 2009), indicating that while the influx of so-called social media like Facebook (Bode, 2012; Gustafsson, 2012; Woolley, Limperos, \& Oliver, 2010) and Twitter (e.g., Ausserhofer \& Maireder, 2013; Burgess \& Bruns, 2012; Larsson \& Moe, 2012, 2013) appears to have made at least some type of mark in this area, the data available tend to point in the direction suggested by what is often referred to as the normalization hypothesis, leading to a "fat democracy" (Davis, 2010), indicating lower degrees of the previously suggested citizen activation, and relatively higher degrees of "politics as usual" (e.g., Margolis \& Resnick, 2000; Wright, 2011).

Social media are often described as allowing the creation and exchange of user-generated content (Stieglitz \& Dang-Xuan, 2012). Twitter is often characterized as a microblog, allowing its users to author publically available updates - or "tweets" - of up to 140 characters each. At the risk of oversimplifying, Twitter is generally used in three different ways, including: undirected messages (with no specific intended recipient), @messages (directed to another specified user), or in the form of retweets (redistributing a message sent by someone else). While discussions of the political and participatory potential of social media like Twitter to some degree seem to echo the overtly optimistic pundits of the past, it is undoubtedly pertinent to study the political uses of these services. This is what this paper seeks to do.

Specifically, while a number of studies have gauged various forms of social media activity in conjunction with parliamentary elections, the scope of research looking into online political conversations "in the everyday lives of the public" (Eveland, Morey, \& Hutchens, 2011, p. 1085) is arguably rather limited (e.g., Anduiza et al., 2009; Ausserhofer \& Maireder, 2013; Hoffman, 2012). While much political activity at the hands of both citizens and elected officials takes place in relation to elections, the study at hand aims towards "a broader understanding of political discussions on Twitter" (Himelboim et al., 2013, p. 17), focusing on aspects of political Twitter use beyond events on "the congressional calendar" (Golbeck, Grimes, \& Rogers, 2010, p. 1618), such as elections. What is presented here is 
a structural analysis of everyday political Twitter use and users in Sweden and Norway. The empirical material consists of 388,875 tweets featuring specific hashtags - thematic keywords included by the users themselves denoting political content - archived during a three-month period. Employing a series of filtering techniques, the analytical focus is placed on the high-end users of these hashtags, specifically, the information they disclose about themselves on their public Twitter profile pages. While Twitter is not immensely popular in the two case countries, it is often seen as an elite medium of sorts (Larsson \& Moe, 2013). The current paper allows for more insight into how these suggested use patterns play out in a clear, thematic setting. Moreover, as the bulk of research on this and related topics tends to emanate from the US context, studies providing insight into political social media use in other countries is sorely needed (as suggested by, Anduiza et al., 2009; Gustafsson, 2012).

\section{Political discussion online: Three perspectives}

As it is problematic to more precisely define what constitutes online citizen political discussion, a considerable number of terms are used to describe these tendencies (e.g., Hoffman, 2012). Indeed, Anduiza et al. suggest that such discussion can be understood as "a multidimensional concept, in which the boundaries between what constitutes participation and what does not are often unclear" (2009, p. 862). Sometimes overlapping in meaning, terms like political discussion (e.g., Himelboim, Gleave, \& Smith, 2009; Papacharissi, 2004; Velasquez, 2012), deliberation (e.g., Dahlgren, 2005; Karppinen, Moe, \& Svensson, 2008; Loveland \& Popescu, 2011), conversation (e.g., Eveland et al., 2011; Papacharissi, 2002), and, quite simply, political talk (e.g., Himelboim et al., 2013; Kavanaugh, Kim, Pérez-Quinones, Schmitz, \& Isenhour, 2008; Walsh, 2004; Wright, 2012) are frequently employed to denote activities pertaining to some aspect of online participation. With this multitude of labels in mind, this paper argues that research regarding the online political participation of citizens has mostly been inspired by one or more of three common approaches: the degree to which such activities correspond to some normative measure of deliberation; the effects of online participation; and, finally, the conceptual area in which this study makes a contribution, assessments of the types of actors involved and the communicative patterns that emerge from their involvement.

As pointed out by Mutz, the relationship between more theoretical and more empirical researchers interested in online deliberation has been "strained at best" (2008, p. 522). Without describing such fractions or the conflicts between them any further, it is probably safe to say that the concept at hand has permeated a considerable amount of research on the topic of online political participation. Often understood in relation to the works of Habermas $(1989,2006)$ regarding the public sphere, deliberative theory essentially proposes that public communication should strive to feature an extensive assortment of pertinent issues, and that arguments and judgments must be fashioned in order to facilitate the "widest possible empowerment" or the "popular inclusion" (Ferree, 2002, p. 296 ff.) of different actors taking part in the discussions. As such, deliberation in terms of political participation can be under- 
stood as "discussion that involves judicious argument, critical listening, and earnest decision making" (Gastil, 2000, p. 22) - arguably a complex blend of concepts to be operationalized for empirical research (for example, see Mutz, 2008; Stromer-Galley, 2007; Wiklund, 2005).

Historically, the concept of media effects and the degree to which they could be said to be salient among media consumers has yielded significant controversy among scholars as well as in society at large. It comes as little surprise, then, that research efforts featuring this particular perspective continue to raise levels of interest in the age of the Internet, and also with regard to the specific topic under investigation here. While Anduiza and colleagues argue that "the generic question about the effect of the Internet on 'political participation' is generally confusing" (2009, p. 862), early studies adopting various dimensions of the effects perspective tended to portray Internet use as something adverse with regards to political (e.g., Putnam, 2000) as well as other forms of participation (Morahan-Martin, 2005). Later efforts presented a view of these processes shifted slightly towards more positive interpretations. As such, studies have found that engagement in a variety of politically themed online fora has resulted in - more often than not limited - degrees of positive effects on the measures employed to gauge engagement in, for example, "civic and political action" (Gil de Zúñiga, 2012), "political talk" (Kavanaugh et al., 2008), and "political involvement" (Kruikemeier, van Noort, Vliegenthart, \& de Vreese, 2013), whether on- or offline. Indeed, such labels again speak to the wide variety of conceptualizations of the topic at hand. As of late, the arrival of so-called social media - like the one under scrutiny here - have again given voice to claims of negative effects by referring to "slacktivism" (H. S. Christensen, 2011; Morozov, 2011). Moreover, scholarly inquiry into such novel channels has also given rise to a series of studies attempting to employ measures of politically themed social media activity to predict election results (e.g., Franch, 2013; Tumasjan, Sprenger, Sandner, \& Welpe, 2010).

The present study, then, adopts the perspective of actors. Research in this direction has often focused on gauging the degree to which previously unengaged members of the populace - understood as "citizens" when compared to groups that are usually engaged in some way (such as politicians or journalists) - are taking part in online political discussions. These studies typically show that those who do not otherwise partake in such discussions can feel more at ease in doing so in online rather than face-to-face settings (Eveland et al., 2011, p. 1084), a finding that appears valid also in studies of Twitter activity (Larsson \& Moe, 2012, 2013; Moe \& Larsson, 2012). As discussed earlier, by broadening the scope of cases included as well as assessing the need to study online political discussions beyond election periods, this study provides insight into online discussions as positioned in the "experiential domain of everyday life" (Dahlgren, 2009, p. 75).

\section{Method}

Eveland et al. (2011) suggest that the bulk of literature on informal political conversation is based on self-report survey measures, with respondents themselves indicating to what 
degree they partake in these types of activities, both on- and offline. As proposed by Vaccari (2012), the "natively digital" (Rogers, 2009) approach favored here is based on collection and analysis of "transactional data generated in real online interactions" (Vaccari, 2012, p. 123), thus providing an alternative to self-report data. The following section outlines the rationale employed for data collection and analysis.

\section{Data collection}

In order to gauge online political discussions on Twitter in the two case countries, the leading hashtags for such activities for Norway were determined to be related to a daily evening newscast (hashtag \#dax18) and a weekly recurring debate show (\#debatten), both airing on the NRK public service broadcaster. For Sweden, the dominant hashtag was found to be \#svpol - a user-generated theme, not specifically related to any media outlets. At the time of data collection, Norway lacked a hashtag similar to \#svpol. As such, while the hashtags studied emanate from different thematic contexts, they effectively fulfill the same functionality in the Norwegian and Swedish contexts. As all three hashtags provide comparably popular spaces for political discussion in each nation's Twittersphere, the argument is made that they are similar enough for the type of analyses to be undertaken here. As the two Norwegian hashtags are not controlled in any way by the Norwegian public service broadcaster (NRK) airing the corresponding shows, they can be expected to feature free debate - much like their Swedish equivalent. Nevertheless, the fact that the studied hashtags are characterized by differing institutional alignments needs to be taken into account when assessing the results presented here.

As already briefly mentioned, hashtags can be described as keywords that allow Twitter users to search and aggregate their tweets on specific topics. Following the approaches adopted by previous research (e.g., Bruns \& Burgess, 2011a; Larsson, 2013b; Larsson \& Moe, 2013), archiving of tweets containing the specified hashtags was initiated on November 21, 2012, using the YourTwapperKeeper service (e.g., Bruns \& Liang, 2012). In order to capture variation regarding levels of activity for each hashtag, the collection process was terminated a little over three months later (March 3, 2013), resulting in a total of 388,875 captured tweets.

While "the growing availability of online social network data" (Bond et al., 2012, p. 298) is indeed an interesting opportunity for scholars of online political behavior, these types of approaches are not without their limitations. Specifically, we should be wary of the inner workings of the Twitter API, which provides a "gardenhose" rather than a "firehose" type access to the data of interest. As such, while the methods typically employed cannot be deemed failsafe when it comes to securing a complete sample (Lewis, Zamith, \& Hermida, 2013; Lomborg, 2012), the demarcation of data collection to focus on specific hashtags such as done here - goes some way towards procurement of a full sample (as suggested by Morstatter, Pfeffer, Liu, \& Carley, 2013). 


\section{Data analysis}

While the approach of looking at both the top and the end of the proverbial "long tail" of Twitter users in studies like this is certainly a valid one (e.g., Bruns \& Stieglitz, 2012), focusing exclusively on high-end users can be helpful in identifying political communities of like-minded Twitter users (Stieglitz \& Dang-Xuan, 2012). While previous studies employed demarcations such as the "top ten" (Larsson \& Moe, 2012, forthcoming) or "top thirty" (Dang-Xuan, Stieglitz, Wladarsch, \& Neuberger, 2013) users, the present study seeks to expand on these delimitations and gauges the top one hundred users of @messages and retweets emanating from the specified hashtags.

The collected tweets were made subject to computational as well as manual modes of analysis (as suggested by Giglietto, Rossi, \& Bennato, 2012; Lewis et al., 2013; Sjovaag \& Stavelin, 2012). First, computational methods allow for relative ease in identifying and sorting cases of specific interests - here, the top one hundred users of @messages and retweets for the archived hashtags. This was performed using a combination of Gawk scripts (Bruns, 2011; Bruns \& Burgess, 2011b) and statistical software. Second, the publically available Twitter profile pages of these users were archived in portable document format (pdf), utilizing a method similar to the one described by Lewis and colleagues (2013, p. 46). While this strategy for data collection undoubtedly creates a "snapshot" of a particular web page (e.g., Brügger, 2011), disregarding the future changes it might undergo (e.g., Karlsson \& Strömbäck, 2010), approaches like this help us delimit online content and make it conducive to analysis. Following archiving, the information on the Twitter profile pages was content analyzed, employing a coding scheme comparable to those favored by similar earlier studies seeking to assess and categorize self-disclosed information regarding professional or ideological inclinations (e.g., Ausserhofer \& Maireder, 2013; Larsson \& Moe, forthcoming; Lewis et al., 2013; Lotan et al., 2011). Beyond elected officials stating their political affiliation, ideological statements were also found to be non-parliamentary - for example, users introducing themselves as a "proud, nationalist Swede" or as "critical of the ongoing Islamization of Norway" were understood as right-wingers in this regard. Distinctions were further made between users identifying as professionals in Media/PR and NGOs/Non-Profits and users identifying as supporting a particular political party - out of which users identifying as elected officials were also coded. Following this, any user that did not provide a professional or ideological statement was coded as a Citizen. In order to gauge coding quality, intra-coder reliability was evaluated by re-coding a random twenty percent sample of the user profiles. Specifically, the Krippendorf's $\triangle$ macro for SPSS was employed (Hayes \& Krippendorff, 2007; Krippendorff, 2008), resulting in an agreement figure of .83 - above the lower bound limit of .70 (Lombard, Snyder-Duch, \& Bracken, 2002).

\section{Results}

To start, figure one 1 depicts the "ebb and flow" of activity on a day-by-day basis yielded by those who included any of the three hashtags in their Twitter messages. 


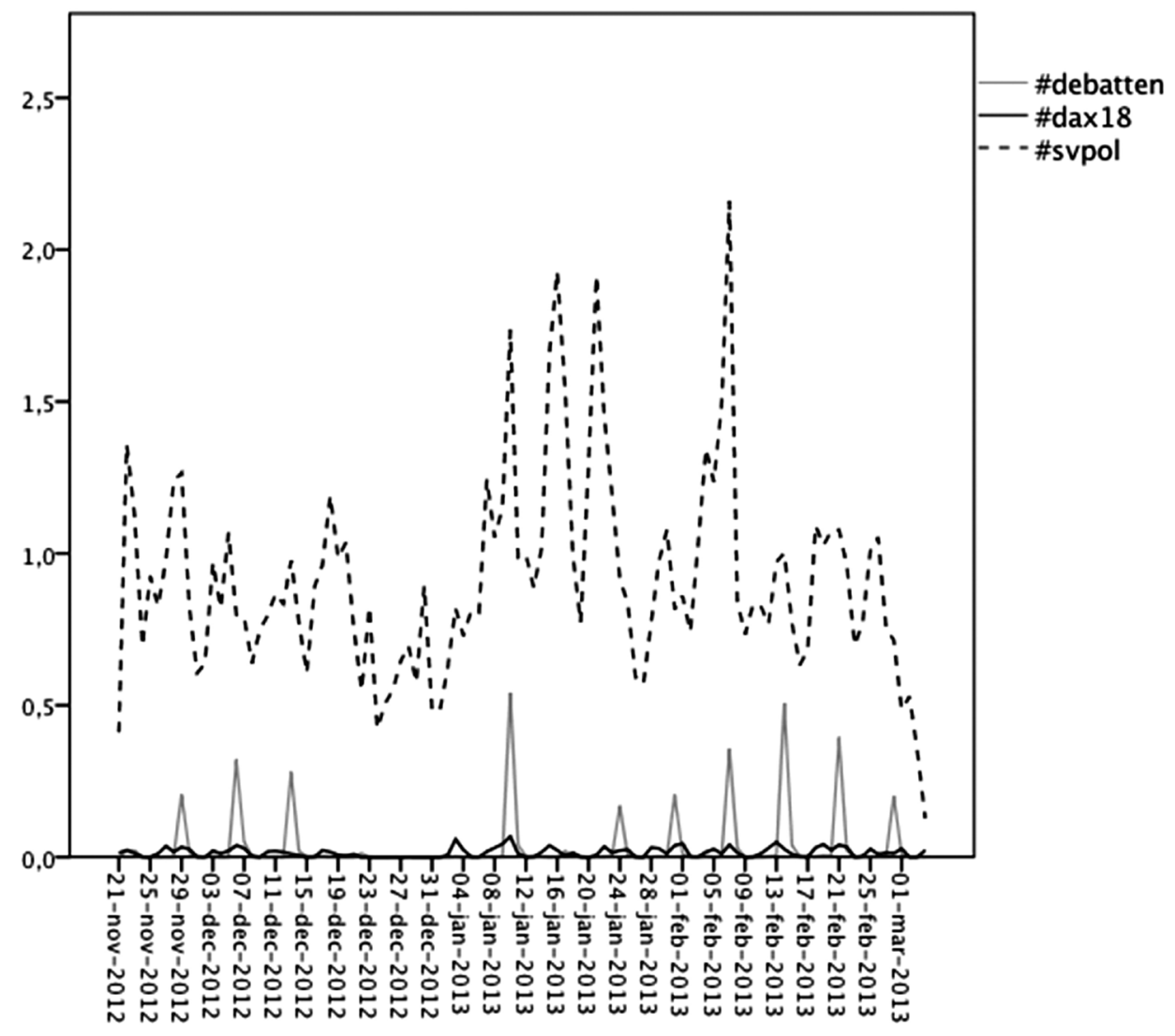

Figure 1. Longitudinal distribution of tweets per hashtag (\% of total amount of tweets per day)

While all timelines bare some similarities to each other - for example, the low point of activity during the 2012 Christmas season - they also exhibit some clear differences. First, activity in the line corresponding to the \#debatten hashtag appears centered around the airtimes of the associated debate show. Second, what could be described as an almost reverse tendency can be discerned for hashtag \#dax18 corresponding to a daily news show on Norwegian public service television. Here, the activity appears rather evenly distributed throughout the periods - throughout the daily newscasts. As such, both Norwegian cases show comparable tendencies to similar broadcast related hashtags found in other contexts (e.g., Bruns \& Stieglitz, 2012; Larsson, 2013b). Finally, the \#svpol hashtag does not exhibit any rule-bound characteristics of the types discussed earlier. As it is not specifically related to any broadcastor other type of regularity-bound media outlet, it is perhaps not entirely unexpected to see this stream of activity baring resemblance to similar hashtags - e.g., the \#auspol variety, denoting Australian political discussions (Highfield, Bruns, \& Harrington, 2012).

As discussed earlier, Twitter users have a number of different modes of communication at their disposal. Table 1 presents an overview of the uses of original tweets, @messages, and retweets as exhibited in the three hashtags. 
Article: Everyday elites, citizens, or extremists?

\begin{tabular}{|c|c|c|c|}
\hline & \#dax18 & \#debatten & \#svpol \\
\hline Original tweets & $3,698 \quad(60)$ & $7,618 \quad(54)$ & $215,853 \quad(58)$ \\
\hline @messages & 578 & 1,337 & 46,113 \\
\hline Retweets & $1,884 \quad(31)$ & $5,046 \quad(37)$ & 106,748 \\
\hline TOTAL & 6,160 (100) & $14,001(100)$ & $368,714(100)$ \\
\hline
\end{tabular}

Table 1. Types of tweets from the three hashtags. N (\%).

While the distribution of types of tweet for each hashtag exhibits some variation, the general indication is one of rather limited employment of the conversational potential of Twitter - the @message. Similarly, the functionality of redistributing tweets sent by others through retweeting is evident in around one third of all tweets, irrespective of hashtag. For all hashtags, then, original tweets - undirected messages sent to a broader, unspecified base of recipients - make up the largest category. Taken together, the results presented in table 1 largely mirror those found in similar studies in the Scandinavian countries (Larsson \& Moe, 2013), while results emanating from other contexts, such as Austria (Ausserhofer \& Maireder, 2013) or Australia (Bruns \& Burgess, 2011a), tend to differ slightly from the distributions reported here.

Turning to the top users identified for each hashtag, for \#dax18 this list of highly active users included 289 individuals (total $N$ of users: 2,142), for \#debatten 321 (total: 4,480) and for \#svpol 258 (total: 48,885). As such, what we are studying here are the top elites active within each hashtag. Table 2 presents the findings from the coding performed regarding the characteristics of users as reported on their Twitter profile pages - specifically, statements regarding ideological preference and professional activities.

\begin{tabular}{|c|c|c|c|}
\hline & \#dax18 & \#debatten & \#svpol \\
\hline Citizens & $145 \quad(50)$ & $128 \quad(39)$ & $73 \quad(28)$ \\
\hline Media/PR & $38 \quad(13)$ & (17) & $35 \quad(14)$ \\
\hline NGOs/Non-profits & $22 \quad(8)$ & (5) & (2) \\
\hline Far left & $0 \quad(0)$ & (0) & (1) \\
\hline Left & $36 \quad(12)$ & $76 \quad(24)$ & $27 \quad(11)$ \\
\hline Right & $43 \quad(15)$ & $38 \quad(12)$ & $32 \quad(12)$ \\
\hline Far right & $5 \quad(2)$ & (3) & $75 \quad(29)$ \\
\hline Pirate Party & (0) & (0) & (3) \\
\hline TOTAL & $289(100)$ & $321(100)$ & $258(100)$ \\
\hline
\end{tabular}

Table 2. Ideological and professional characteristics of top Twitter users. N (\%).

For the two Norwegian hashtags, the Citizen category is the dominant one (accounting for fifty percent of the top \#dax18 users, thirty-nine percent for \#debatten), followed by Twitter users issuing their support for established political parties on both sides of the political 
spectra as well as by a category made up of Media/PR professionals. While supporters of right-wing political parties appear similarly represented in both Norwegian hashtags (fifteen and twelve percent respectively), the \#debatten Twitter community boasts more than double the amount of left-wing political party supporters. A similar, yet more clearly stated dominance of a particular political persuasion is apparent for the \#svpol hashtag. While users in the Citizen category make up twenty-eight percent of the total number of top users here, the largest user category in the Swedish case are users identifying as supporters of far-right political ideologies (representing twenty-nine percent of users). In sum, while we cannot be entirely sure that "political fakes" (Wilson, 2011) - i.e., parody accounts - are not part of our sample, the dominance of certain political and professional groups in the three hashtag communities provide us with some insight into the makeup of those who frequently partake in these hashtagged fora. With regards to the more communicative aspects of such activities, tables 3 and 4 present results regarding the uses of @messages and retweets among the identified different groups of users.

\begin{tabular}{l|c|c|c|c|c|c|} 
& \multicolumn{2}{|c|}{ \#svpol } & \multicolumn{2}{c|}{ \#debatten } & \multicolumn{2}{|c|}{ \#svpol } \\
\cline { 2 - 8 } & $\begin{array}{c}\text { @messages } \\
\text { sent }\end{array}$ & $\begin{array}{c}\text { @messages } \\
\text { received }\end{array}$ & $\begin{array}{c}\text { @messages } \\
\text { sent }\end{array}$ & $\begin{array}{c}\text { @messages } \\
\text { received }\end{array}$ & $\begin{array}{c}\text { @messages } \\
\text { sent }\end{array}$ & $\begin{array}{c}\text { @messages } \\
\text { received }\end{array}$ \\
\hline Citizen & 61 & 43 & 49 & 28 & 32 & 29 \\
Media/PR & 11 & 17 & 13 & 21 & 3 & 8 \\
\hline NGOs/Non-profits & 3 & 6 & 4 & 5 & 1 & 2 \\
\hline Far left & 0 & 0 & 0 & 0 & 1 & 1 \\
Left & $9(8)$ & $12(10)$ & $19(13)$ & $21(17)$ & $7(5)$ & $16(14)$ \\
\hline Right & $16(12)$ & $21(20)$ & $12(10)$ & $23(22)$ & $10(6)$ & $10(9)$ \\
\hline Far right & 0 & $1(1)$ & $3(3)$ & $2(2)$ & $42(10)$ & $35(20)$ \\
\hline Pirate Party & 0 & 0 & 0 & 0 & $4(1)$ & $4(4)$ \\
\hline TOTAL & $100(20)$ & $100(31)$ & $100(26)$ & $100(31)$ & $100(22)$ & $100(47)$ \\
\hline
\end{tabular}

Table 3. Top 100 senders and receivers of @messages. N (N of politicians).

Table 3 presents the political or professional classifications of the users as evident from their respective Twitter profile pages. Figures in parenthesis indicate the number of users in that particular category (i.e., in that individual table cell) who identified themselves as elected political officials on some level of government.

For the two Norwegian hashtags, the ideological division previously noted when comparing \#dax18 and \#debatten appears to have diminished slightly - also when focusing within each hashtag rather than comparing the two - when assessing the specific practices presented here. While Citizen is still the dominant category for both hashtags, the results suggest the prominence of politically inclined citizens taking part in discussing the themes brought up in television shows corresponding to the hashtags under study. 
For Sweden, this political engagement appears to take on a rather different character. The dominance of self-professed far-right supporters is admittedly even more stated here, indicating that such extreme voices appear to be dominating much of the discussion - understood here as @messages - while other groups of users appear less eager to strike up conversations. Finally, while there is considerable variation among the hashtags regarding the number of elected officials taking part, as a group, these participants tend to receive more messages than they send. While the results presented in table 3 suggest that this would appear especially true in the Swedish case, similar patterns of usage have been uncovered by previous research in both countries (e.g., Larsson \& Moe, 2012, 2013; Moe \& Larsson, 2012).

Finally, table 4 depicts the top senders and receivers of retweets.

\begin{tabular}{|c|c|c|c|c|c|c|}
\hline & \multicolumn{2}{|c|}{ \#dax18 } & \multicolumn{2}{|c|}{ \#debatten } & \multicolumn{2}{|c|}{ \#svpol } \\
\hline & $\begin{array}{c}\text { Retweets } \\
\text { sent }\end{array}$ & $\begin{array}{l}\text { Retweets } \\
\text { received }\end{array}$ & $\begin{array}{c}\text { Retweets } \\
\text { sent }\end{array}$ & $\begin{array}{l}\text { Retweets } \\
\text { received }\end{array}$ & $\begin{array}{c}\text { Retweets } \\
\text { sent }\end{array}$ & $\begin{array}{l}\text { Retweets } \\
\text { received }\end{array}$ \\
\hline Citizen & 53 & 43 & 46 & 20 & 27 & 22 \\
\hline Media/PR & 11 & 18 & 14 & 29 & 3 & 27 \\
\hline NGOs/Non-profits & 6 & 14 & 4 & 5 & 1 & 3 \\
\hline Far left & 0 & 0 & 0 & 0 & 1 & 1 \\
\hline Left & $11 \quad(9)$ & $10 \quad(9)$ & $23(20)$ & $34(32)$ & $14(10)$ & 11 (11) \\
\hline Right & $17(12)$ & 15 (13) & $11(10)$ & $10(10)$ & $10 \quad(9)$ & 10 \\
\hline Far right & $2(2)$ & 0 & $2 \quad(1)$ & $2(2)$ & (5) & 29 \\
\hline Pirate Party & 0 & 0 & 0 & 0 & (1) & $3 \quad(2)$ \\
\hline TOTAL & $100(23)$ & $100(22)$ & 100 (31) & $100(44)$ & $100(25)$ & $100(31)$ \\
\hline
\end{tabular}

Table 4. Top 100 senders and receivers of retweets. $N$ ( $N$ of politicians).

Table 4 is structured much in the same manner as table 3 , and as such, the same guidelines for interpretation should be applied. Indeed, similar patterns to those presented previously regarding what kind of users take the roles of senders and receivers are apparent here. While the two Norwegian hashtags appear dominated by users preferring limited amounts of self-disclosure, the distributions for the \#debatten hashtag is again somewhat skewed towards activity from the left side of the political spectrum - with politicians leaning in that particular direction receiving the majority of retweets. For the \#svpol hashtag, a similar skew is again found towards users indicating support of the far right side of contemporary politics. Much like table 3 , the number of far right supporters identifying as elected officials appears relatively smaller when compared to those prescribing to other political persuasions. Furthermore, regarding the activity of elected officials, the data presented in parentheses featured in the bottom row of table 4 indicate that for \#debatten and \#svpol, this particular group of users can be understood along the lines of what Larsson and Moe 
(2012, p. 740) classified as an elite group of Twitter users - their messages being redistributed to relatively higher degrees than they themselves retweet the messages sent by others.

In sum, the results presented here suggest that the broadcast-related Norwegian hashtags are more oriented towards what could be described as a "mainstream" of political debate, due to the internal distribution of non-disclosure and traditional left- or right-leaning actors. In contrast, the Swedish hashtag is not related to any specific media outlet and appears dominated by more extreme political pundits, supporters, and politicians. While this is not to suggest a direct link or correlation between variety of hashtag and the types of users who seek out these arenas for communication, other tendencies and interpretations that follow from these results can be presented. This is done in the following section.

\section{Discussion}

For any iteration of the Internet - be it 1.0,2.0, or even 3.0 - to function efficiently as a forum for human communication, design and structural choices regarding the online environment must be planned and executed accordingly. As suggested by Loveland and Popescu, our online activity "generally takes various forms that are encouraged or discouraged by various environments" (2011, p. 16). Indeed, the very basic observation that aspects of technological design can produce or hinder political participation and help usher in certain outcomes is supported by a considerable amount of research (e.g., Freelon, 2010). With the influx of supposedly easy-to-use, adaptable, and connective social media such as Twitter, these services have supposedly "changed the physics of information diffusion" (Stieglitz \& Dang-Xuan, 2012, p. 1). While optimistic statements like these - of which there are plenty - are characterized by a certain degree of exaggeration, the results presented in this study indicate that a wide variety of users - not only media professionals and politicians - appear to take part in the thematic discussions studied. Such a claim seems especially valid when considering the two Norwegian hashtags. Both related to broadcast events, the structure of Twitter activity as presented here indicates that Twitter could be functioning as some sort of "online watercooler" (Stelter, 2010) or "virtual loungeroom" (Harrington, Highfield, \& Bruns, 2012, p. 13). As such, the activity of tweeting in relation to television shows can be likened to practices of "audiencing" (Fiske, 1992) - of taking part in a more or less temporary community, discussing mediated content with others through @messaging, airing your own opinion through original tweets or commenting on the statements made by others through retweets (see also Bruns \& Stieglitz, 2012). Whether the relative popularity of these practices is the result of the spread of Twitter use among the citizenry (e.g., Brynolf, 2013) or of a widened scope of analysis when compared to previous research efforts (e.g., compared to Larsson, 2013b) is difficult to ascertain from the data presented here. Future studies will perhaps be able to gauge these developments in a longitudinal fashion (see more on this below).

Widened use of Twitter or not, we must not lose sight of the fact that the amount of conversation (using the @message functionality) is arguably limited. Moreover, the results 
indicate that groups of users who expressed professional affiliation or political inclination did indeed appear to make clear marks on the activities featured under the respective hashtagged headings. With regards to the former group of users, this is evident in both countries - indeed, as previous research on Twitter use in both Norway (Moe \& Larsson, 2012) and Sweden (C. Christensen, 2013; Larsson \& Moe, 2012) has indicated, media and PR professionals tend to frequently be high-end users of the service under scrutiny here. While such previous studies have often focused on Twitter use in conjunction with elections, the tendency for journalists and other media workers to take to the fore of Twitter is apparent also here - albeit in a slightly diminished fashion.

Users who chose to share their political persuasions through their Twitter profiles also made a distinct mark, apparent in the results presented. For Norway, while there was some variation between supporters of the left and right, the bulk of those who expressed these types of preferences could undoubtedly be regarded as part of the mainstream of contemporary political debate. As the numbers in parenthesis in tables 3 and 4 indicated, many of the top Norwegian users who provided political indications were also elected to serve at some level of government. As shown by previous research, the role of politicians in Twitter debates should not be underestimated. This tendency, however, is partly reversed for the Swedish case. While groups of Twitter users subscribing to mainstream ideological views identify as politicians to similar degrees here as for the Norwegian hashtags, only a limited number of such representatives appear among the single dominant group of users - those subscribing to far-right political viewpoints. Where the Norwegian hashtags are both related to and created by recurring broadcast events, presumably drawing in a more mainstream audience, the dominance of far-right users in the \#val2010 hashtag could be expected to render the hashtag almost as a parallel to political debate taking place elsewhere. Similar results akin almost to hashtag "takeovers" by extreme political groups have been reported also in the Australian \#auspol hashtag (Bruns \& Burgess, 2012; Highfield et al., 2012), tentatively suggesting that these types of online foci could be the result of a strategy of marginalized ideological supporters. While it is difficult to make any strong claims regarding this based on the results presented here, such an approach at the hands of these types of groups would seem logical given their supposed limited access to traditional media outlets. Indeed, the claim made by Jackson and Lilleker that "fringe parties [...] would attempt to exploit free channels to a far greater extent" (2009, p. 240) seems valid also outside of the UK context - indeed, a claim baring similarity to those aired regarding the so-called innovation hypothesis during the early days of research into online political communication (e.g., Larsson, 2013a; Schweitzer, 2008).

In sum, this study has shown that while Twitter hashtags can indeed provide a venue for citizens, a significant amount of activity is undertaken by established political actors as well as niche political groups. The degree to which such established actors take part in contexts like these should not come as too much of a surprise, as many citizens lack the "time, money, or cognitive or organizational resources" (Anduiza et al., 2009, p. 865). While 
measures to increase the on- or offline civic activity of members of the public are generally laudable, the findings here beg the question - especially when assessing the Swedish case - where are the established politicians to enter into debate with the far-right supporters found in \#svpol? While this paper did not look into the context of what is actually being said in these hashtagged environments, it is safe to assume supporters of a certain, extreme agenda would carry such opinions forward. If such extreme views - emanating from any side of the political spectrum - are not challenged, political discussions on Twitter or elsewhere can hardly fulfill the role prescribed to them by pundits and scholars alike.

While the study presented in this paper has provided insight into everyday political uses of Twitter, it carries with it a set of limitations that need to be clearly addressed. Specifically, this will be addressed by discussing two distinct sets of limitations, the first of which deals with the content of the tweets themselves. As the present study has provided an overarching structural analysis, rather than a focus on the actual substance of the tweets, we can draw very limited conclusions regarding the quality of the conversations mapped out above. As pointed out by Tumasjan and colleagues, the practice of "turning to the 'Twittersphere' as an indicator of political opinion" (2010, p. 403) could be substantiated by a sound analysis of what is actually being said, and how it is being said, on Twitter as well as on other social media platforms. Future studies, then, could perhaps expand on the approach favored here and employ some means of content analysis - qualitative or qualitative - of the messages sent. While the concept of what constitutes "quality" in political conversation is under discussion, such an approach could perhaps shed light on these issues by integrating coding schemes, content classification criteria, and other rationales available in the literature (e.g., Christensen \& Bengtsson, 2011; Eveland et al., 2011; Stromer-Galley, 2007). With regards to the brevity of Twitter messages, Himelboim and colleagues suggest that "short political messages [...] are a common practice in other forms of political communication" (2013, p. 2). Thus, it remains to be seen whether different tweeting practices can be deemed as exposing some desirable characteristic, or if it is more akin to "pointless babble" (Pearanalytics, 2009).

A second set of limitations has to do with the users of the service under study. As this paper has scrutinized the characteristics of the top users of political hashtags by collecting data from their respective profile pages, such an approach - while informative - can only describe to a certain extent the individual characteristics of Twitter users who employ the service to engage in everyday political conversation. While other forms of self-report data, such as surveys or interviews, have helped researchers gain insight into the mindsets and socio-demographic characteristics of online political discussants, such approaches are potentially marred by various forms of social desirability bias (e.g., Brady, 1999). As such, while this paper has provided a structural account of political activity in the online realm, future studies could do so in other perhaps more qualitative manners, further gauging the relevant characteristics of those involved - and how they interpret and make sense of the hashtagged fora they take part in. 
In conclusion, the argument is made that while Twitter and Facebook are among the more popular social media services of today, such popularities are bound to come to an end when some new service makes its claim for the online audience. Thus, we need to make sure that our instruments for inquiry - the way we ask our questions or construct our coding sheets - are "stress tested" also for future online platforms. This is almost certainly easier said than done. As technology changes so quickly, suitably aligned research instruments will enhance the quality of not only our present scholarly inquiries, but also of those to come in the future.

\section{References}

Anduiza, E., Cantijoch, M., \& Gallego, A. (2009). Political Participation and the Internet - A Field Essay. Information, Communication \& Society, 12(6), 860-878.

Ausserhofer, J., \& Maireder, A. (2013). National Politics on Twitter. Information, Communication \& Society, 16(3), 291-314.

Bimber, B., \& Copeland, L. (2013). Digital Media and Traditional Political Participation Over Time in the U.S. Journal of Information Technology \& Politics, 10(2), 125-137.

Bode, L. (2012). Facebooking It to the Polls: A Study in Online Social Networking and Political Behavior. Journal of Information Technology \& Politics, 9(4), 352-369.

Bond, R.M., Fariss, C.J., Jones, J.., Kramer, A.D., Marlow, C., Settle, J.E. et al. (2012). A 61-million-person experiment in social influence and political mobilization. Nature, 489(7415), 295-298.

Brady, H. (1999). Political participation. In J. Robinson., Shaver P. \& Whitesman, L (Eds.), Measures of Political Attitudes (pp. 737-801). San Diego, CA: Academic Press.

Bruns, A. (2011). How Long Is a Tweet? Mapping Dynamic Conversation Networks On Twitter using Gawk and Gephi. Information, Communication \& Society, 15(9), 1323-1351.

Bruns, A., \& Burgess, J. (2011a). \#ausvotes - How Twitter Covered the 2010 Australian Federal Election. Communication, Politics \& Culture, 44(2), 37-56.

Bruns, A., \& Burgess, J. (2011b). Mapping Online Publics: Gawk Scripts for Twitter Processing Consulted on April 16, 2013. http://mappingonlinepublics.net/2011/06/22/gawk-scripts-for-processing-twitter-datavol-1/

Bruns, A., \& Burgess, J. (2012). Notes towards the Scientific Study of Public Communication on Twitter. In A. Tokar, M. Beurskens, S. Keuneke, M. Mahrt, I. Peters, C. Puschmann \& T.v. Treeck (Eds.), Science and the Internet (pp. 159-169). Düsseldorf: Düsseldorf University Press.

Bruns, A., \& Liang, Y. E. (2012). Tools and methods for capturing Twitter data during natural disasters. First Monday, 17(4).

Bruns, A., \& Stieglitz, S. (2012). Quantitative Approaches to Comparing Communication Patterns on Twitter. Journal of Technology in Human Services 30(3-4), 160-185.

Brügger, N. (2011). Web archiving-Between past, present, and future. In M. Consalvo \& C. Ess (Eds.), The Blackwell handbook of Internet Studies (pp. 24-42). Oxford, UK: Wiley-Blackwell.

Brynolf, H. (2013). Twitter Census: En rapport om Twitter i Sverige. Stockholm: Intellecta Corporare.

Burgess, J., \& Bruns, A. (2012). (Not) the Twitter Election. Journalism Practice, 6(3), 384-402.

Calenda, D., \& Meijer, A. (2009). Young People, the Internet and Political Participation - Findings of a Web Survey in Italy, Spain and the Netherlands. Information, Communication \& Society, 12(6), 879-898. 
Castells, M. (2004). The power of identity (2nd ed.). Malden, Mass; Oxford: Blackwell.

Chadwick, A. (2006). Internet politics : states, citizens, and new communication technologies. New York: Oxford University Press.

Christensen, C. (2013). @Sweden: Curating a Nation on Twitter. Popular Communication, 11(1), 30-46.

Christensen, H.S. (2011). Political activities on the Internet: Slacktivism or political participation by other means? First Monday, 16(2).

Christensen, H.S., \& Bengtsson, Å. (2011). The Political Competence of Internet Participants. Information, Communication \& Society, 14(6), 896-916.

Dahlberg, L. (2011). Re-constructing digital democracy: An outline of four 'positions'. New Media \& Society, 13(6), 855-872.

Dahlgren, P. (2005). The Internet, Public Spheres, and Political Communication: Dispersion and Deliberation. Political Communication, 22(2), 147-162.

Dahlgren, P. (2009). Media and Political Engagement: Citizens, Communication, and Democracy. Cambridge: Cambridge UP.

Dang-Xuan, L., Stieglitz, S., Wladarsch, J., \& Neuberger, C. (2013). An Investigation of Influentials and the Role of Sentiment in Political Communication on Twitter during Election Periods. Information, Communication \& Society, 16(5), 795-825.

Davis, A. (2010). New media and fat democracy: the paradox of online participation1. New Media \& Society, 12(5), 745-761.

Eveland, W.P., Morey, A.C., \& Hutchens, M.J. (2011). Beyond Deliberation: New Directions for the Study of Informal Political Conversation from a Communication Perspective. Journal of Communication, 61(6), 1082-1103.

Ferree, M.M. (2002). Four models of the public sphere in modern democracies. Theory and Society, 31(3), 289-324.

Fiske, J. (1992). Audiencing: A cultural studies approach to watching television. Poetics, 21(4), 345-359.

Franch, F. (2013). (Wisdom of the Crowds)2: 2010 UK Election Prediction with Social Media. Journal of Information Technology \& Politics, 10(1), 57-71.

Freelon, D.G. (2010). Analyzing online political discussion using three models of democratic communication. New Media \& Society, 12(7), 1172-1190.

Gastil, J. (2000). By popular demand : revitalizing representative democracy through deliberative elections. Berkeley: University of California Press.

Giddens, A. (2002). Runaway world : how globalisation is reshaping our lives. London: Profile Books.

Giglietto, F., Rossi, L., \& Bennato, D. (2012). The Open Laboratory: Limits and Possibilities of Using Facebook, Twitter, and YouTube as a Research Data Source. Journal of Technology in Human Services, 30(3-4), 145-159.

Gil de Zúñiga, H. (2012). Social Media Use for News and Individuals' Social Capital, Civic Engagement and Political Participation. Journal of Computer-Mediated Communication, 17(3), 319-336.

Golbeck, J., Grimes, J.M., \& Rogers, A. (2010). Twitter Use by the US Congress. Journal of the American Society for Information Science and Technology, 61(8), 1612-1621.

Gustafsson, N. (2012). The subtle nature of Facebook politics: Swedish social network site users and political participation. New Media \& Society, 14(7), 1111-1127.

Habermas, J. (1989). The structural transformation of the public sphere : an inquiry into a category of bourgeois society. Cambridge: Polity Press.

Habermas, J. (2006). Political communication in media society: Does democracy still enjoy an epistemic dimension? The impact of normative theory on empirical research. Communication Theory, 16(4), 411-426.

Harrington, S., Highfield, T.J., \& Bruns, A. (2012). More than a backchannel: Twitter and television. In J.M. Noguera (Ed.), Audience Interactivity and Participation (pp. 13-17). Brussels, Belgium. 
Hayes, A.F., \& Krippendorff, K. (2007). Answering the call for a standard reliability measure for coding data. Communication Methods and Measures, 1(1), 77-89.

Highfield, T., Bruns, A., \& Harrington, S. (2012). \#auspol, \#qldpol, and \#wapol: Twitter and the New Australian Political Commentariat. Paper presented at the Association of Internet Researchers conference, Salford, UK.

Himelboim, I., Gleave, E., \& Smith, M. (2009). Discussion catalysts in online political discussions: Content importers and conversation starters. Journal of Computer-Mediated Communication, 14(4), 771-789.

Himelboim, I., McCreery, S., \& Smith, M. (2013). Birds of a Feather Tweet Together: Integrating Network and Content Analyses to Examine Cross-Ideology Exposure on Twitter. Journal of Computer-Mediated Communication, 18(2), 40-60.

Hindman, M.S. (2009). The myth of digital democracy. Princeton: Princeton University Press.

Hoffman, L.H. (2012). Participation or Communication? An Explication of Political Activity in the Internet Age. Journal of Information Technology \& Politics, 9(3), 217-233.

Jackson, N.A., \& Lilleker, D.G. (2009). Building an Architecture of Participation? Political Parties and Web 2.0 in Britain. Journal of Information Technology \& Politics, 6(3), 232-250.

Kalnes, Ø. (2009). Norwegian Parties and Web 2.0. Journal of Information Technology \& Politics, 6(3), 251-266.

Karlsson, M., \& Strömbäck, J. (2010). Freezing The Flow of Online News -- Exploring Approaches to the Study of the Liquidity of Online News. Journalism Studies, 11(1), 2-19.

Karppinen, K., Moe, H., \& Svensson, J. (2008). Habermas, Mouffe and political communication. A case for theoretical eclecticism. Javnost-the Public, 15(3), 5-22.

Kavanaugh, A., Kim, B.J., Pérez-Quinones, M.A., Schmitz, J., \& Isenhour, P. (2008). Net Gains in Political Participation: Secondary Effects of Internet on Community. Information, Communication \& Society, 11(7), 933-963.

Krippendorff, K. (2008). Systematic and Random Disagreement and the Reliability of Nominal Data. Communication Methods and Measures, 2(4), 323-338.

Kruikemeier, S., van Noort, G., Vliegenthart, R., \& de Vreese, C.H. (2013). Getting closer: The effects of personalized and interactive online political communication. European Journal of Communication, 28(1), 53-66.

Larsson, A.O. (2013a). "Rejected Bits of Program Code": Why Notions of "Politics 2.0" Remain (Mostly) Unfulfilled. Journal of Information Technology \& Politics, 10(1), 72-85.

Larsson, A.O. (2013b). Tweeting the viewer - Use of Twitter in a talk show context. Journal of Broadcasting and Electronic Media, 57(2), 135-152.

Larsson, A.O., \& Moe, H. (2012). Studying political microblogging: Twitter users in the 2010 Swedish election campaign. New Media \& Society, 14(5), 729-747.

Larsson, A.O., \& Moe, H. (2013). Twitter in Politics and Elections - Insights from Scandinavia. In A. Bruns, J. Burgess, K. Weller, C. Puschmann \& M. Mahrt (Eds.), Twitter and Society. New York: Peter Lang.

Larsson, A.O., \& Moe, H. (2013). Representation or Participation? Twitter Use During the 2011 Danish Election Campaign. Javnost - The Public, 20(1), 71-88

Lewis, S.C., Zamith, R., \& Hermida, A. (2013). Content Analysis in an Era of Big Data: A Hybrid Approach to Computational and Manual Methods. Journal of Broadcasting \& Electronic Media, 57(1), 34-52.

Lilleker, D.G., \& Koc-Michalska, K. (2012). Online political communication strategies: MEPs, e-representation and self-representation. Journal of Information Technology \& Politics, 10(2), 190-207

Lombard, M., Snyder-Duch, J., \& Bracken, C.C. (2002). Content analysis in mass communication: Assessment and reporting of intercoder reliability. Human Communication Research, 28(4), 587-604.

Lomborg, S. (2012). Researching Communicative Practice: Web Archiving in Qualitative Social Media Research. Journal of Technology in Human Services, 30(3-4), 219-231. 
Lotan, G., Graeff, E., Ananny, M., Gaffney, D., Pearce, I., \& boyd, d. (2011). The Revolutions Were Tweeted: Information Flows during the 2011 Tunisian and Egyptian Revolutions. International Journal of Communication, 5, 1375-1405.

Loveland, M., \& Popescu, D. (2011). Democracy on the Web. Information, Communication \& Society, 14(5), 684-703.

Margolis, M., \& Resnick, D. (2000). Politics as usual : the cyberspace "revolution". London: SAGE.

Moe, H., \& Larsson, A.O. (2012). Twitterbruk under valgkampen 2011. Norsk Medietidsskrift, 19(2), 151-162.

Morahan-Martin, J. (2005). Internet Abuse: Addiction? Disorder? Symptom? Alternative Explanations? Social Science Computer Review, 23(1), 39-48.

Morozov, E. (2011). The net delusion : the dark side of internet freedom. New York: Public Affairs.

Morstatter, F., Pfeffer, J., Liu, H., \& Carley, K.M. (2013). Is the Sample Good Enough? Comparing Data from Twitter's Streaming API with Twitter's Firehose. Retreived February 21, 2014, from Association for the Advancement of Artificial Intelligence website: http://arxiv.org/abs/1306.5204

Mutz, D.C. (2008). Is deliberative democracy a falsifiable theory? Annual Review of Political Science, 11, 521538.

Norris, P. (2002). Democratic phoenix : reinventing political activism. Cambridge: Cambridge University Press. Papacharissi, Z. (2002). The virtual sphere: The internet as a public sphere. New Media \& Society, 4(1), 9-27.

Papacharissi, Z. (2004). Democracy online: civility, politeness, and the democratic potential of online political discussion groups. New Media \& Society, 6(2), 259-283.

Pearanalytics. (2009). Twitter study - August 2009. Retrieved February 21, 2014 from: http://www.pearanalytics.com/wp-content/uploads/2012/12/Twitter-Study-August-2009.pdf.

Polat, R.K. (2005). The Internet and Political Participation: Exploring the Explanatory Links. European Journal of Communication, 20(4), 435-459.

Putnam, R.D. (2000). Bowling alone : the collapse and revival of American community. New York: Simon \& Schuster.

Rogers, R. (2009). The End of the virtual-Digital methods. Amsterdam: Amsterdam University Press.

Schweitzer, E.J. (2008). Innovation or Normalization in E-Campaigning? A Longitudinal Content and Structural Analysis of German Party Websites in the 2002 and 2005 National Elections. European Journal of Communication, 23(4), 449-470.

Sjovaag, H., \& Stavelin, E. (2012). Web media and the quantitative content analysis: Methodological challenges in measuring online news content. Convergence: The International Journal of Research into New Media Technologies, 18(2), 215-229

Skoric, M.M., Ying, D., \& Ng, Y. (2009). Bowling Online, Not Alone: Online Social Capital and Political Participation in Singapore. Journal of Computer-Mediated Communication, 14(2), 414-433.

Stelter, B. (2010). Water-Cooler Effect: Internet Can Be TV's Friend, The New York Times February 23, 2010. Retrieved February 21, 2014 from: http://www.nytimes.com/2010/02/24/business/media/24cooler. html?_r=0.

Stieglitz, S., \& Dang-Xuan, L. (2012). Social media and political communication: a social media analytics framework. Social Network Analysis and Mining, 3(4), 1277-1291.

Stromer-Galley, J. (2007). Measuring Deliberation's Content: A Coding Scheme. Journal of Public Deliberation, 3(1), 1-35.

Tichenor, P.J., Donohue, G.A., \& Olien, C.N. (1970). Mass Media Flow and Differential Growth in Knowledge. The Public Opinion Quarterly, 34(2), 159-170.

Tumasjan, A., Sprenger, T.O., Sandner, P.G., \& Welpe, I.M. (2010). Election Forecasts With Twitter: How 140 Characters Reflect the Political Landscape. Social Science Computer Review, 29(4), 402-418. 
Tumasjan, A., Sprenger, T.O., Sandner, P.G., \& Welpe, I.M. (2010, May 23-26). Predicting elections with Twitter: What 140 characters reveal about political sentiment. Paper presented at the the Fourth International AAAI Conference on Weblogs and Social Media, George Washington University, Washington, DC.

Vaccari, C. (2012). From echo chamber to persuasive device? Rethinking the role of the Internet in campaigns. New Media \& Society. 15(1), 109-127.

Velasquez, A. (2012). Social media and online political discussion: The effect of cues and informational cascades on participation in online political communities. New Media \& Society, 14(8), 1286-1303.

Walsh, K.C. (2004). Talking about politics: informal groups and social identity in American life. Chicago, III. ; London: University of Chicago Press.

Wiklund, H. (2005). A Habermasian analysis of the deliberative democratic potential of ICT-enabled services in Swedish municipalities. New Media \& Society, 7(2), 247-270.

Wilson, J. (2011). Playing with politics: Political fans and Twitter faking in post-broadcast democracy. Convergence: The International Journal of Research into New Media Technologies, 17(4), 445-461.

Woolley, J.K., Limperos, A. M., \& Oliver, M. B. (2010). The 2008 Presidential Election, 2.0: A Content Analysis of User-Generated Political Facebook Groups. Mass Communication and Society, 13(5), 631-652.

Wright, S. (2011). Politics as usual? Revolution, normalization and a new agenda for online deliberation. New Media \& Society, 14(2), 244-261.

Wright, S. (2012). From "Third Place" to "Third Space”: Everyday Political Talk in Non-Political Online Spaces. Javnost-the Public, 19(3), 5-20.

Zittel, T. (2009). Lost in Technology? Political Parties and the Online Campaigns of Constituency Candidates in Germany's Mixed Member Electoral System. Journal of Information Technology \& Politics, 6(3), 298311.

Anders Olof Larsson

Postdoctoral Research Fellow, PhD

Department of Media and Communication

University of Oslo

a.o.larsson@media.uio.no 